\title{
Monocyte Plasminogen Activator Inhibitor 2 (PAI-2) Inhibits u-PA-mediated Fibrin Clot lysis and Is Cross-linked to Fibrin
}

\author{
Helen Ritchie ${ }^{1}$, Linda A. Robbie ${ }^{1,2}$, Seonag Kinghom ${ }^{1}$, Rachel Exley ${ }^{1}$, Nuala A. Booth ${ }^{1}$ \\ From the Departments of ${ }^{1}$ Molecular and Cell Biology and ${ }^{2}$ Medic ine and Therapeutics, \\ University of Aberdeen, Aberdeen, UK
}

\begin{abstract}
Summary
Plasminogen activator inhibitor 2 (PAI-2) is a major product of activated human monocytes. Here we show that monocytes inhibited u-PA- but not t-PA-mediated fibrinolysis, by secreting PAI-2 into an overlying fibrin clot. Extracts of arterial and venous human thrombi were found to contain active PAI-2. PAI-2 was cross-linked to fibrin in a reaction catalyzed by two major transglutaminases (TG), tissue TG and factor XIII. The activity of PAI-2 was not affected by such crosslinking. Cross-linking of PAI-2 to fibrin was inhibited by Tridegin, a specific inhibitor of TG, and also by EDTA and iodoacetamide. The use of competitive peptides mimicking the loop between helices $\mathrm{C}$ and D of PAI-2 identified Gln 83 and 86 as residues important in crosslinking. This study defines a mechanism by which PAI-2 is localized to fibrin, where it acts as an effective inhibitor of u-PA-mediated fibrinolysis.
\end{abstract}

\section{Introduction}

Fibrin is deposited as a result of the coagulation cascade, and persistence of fibrin is dependent on the local balance of plasminogen activators (PAs) and plasminogen activator inhibitors (PAIs). Plasmin, the active serine protease that mediates degradation of fibrin, is generated from the zymogen, plasminogen, by urokinase (u-PA) or tissuetype PA (t-PA). PAI-1 and PAI-2 inhibit plasmin generation by formation of a 1:1 stoichiometric complex with u-PA and t-PA (reviewed in 1). Persistence of fibrin in local environments such as the atherosclerotic plaque indicates an imbalance in fibrinolysis (2). Increased PAI-1 is one such imbalance, and it has been shown that PAI-1 mRNA and antigen are increased in the atherosclerotic vessel wall and also in human thrombi (3-6). PAI-2 has recently been found to be up-regulated in the atherosclerotic plaque (7). PAI-2, unlike PAI-1, is not detected in normal plasma but is detected during pregnancy (8). The distribution of PAI-2 in vivo has not been fully established. However, it is likely that local production of PAI-2 in various tissues is important, and PAI-2 has been detected in the epidermis, in inflamed tissues and in the placenta (9-11). The cell types that express PAI-2 in these situations are keratinocytes, monocytes, and trophoblasts, respectively. There is much

Correspondence to: Helen Ritchie, PhD, Dept of Molecular and Cell Biology, University of Aberdeen, Institute of Medical Sciences, Aberdeen, Scotland, UK, AB25 2ZD - Tel.: +44-1224-681818 ext 54575; FAX Number: +44-1224-273144; E-mail - h.ritchie@abdn.ac.uk

This study was supported by The Marion Fernando Trust and The British Heart Foundation and by a vacation studentship to SK from The Wellcome Trust. more information available on the expression and regulation of PAI-2 in vitro. Many cell types express PAI-2, including monocytes, endothelial cells, smooth muscle cells, fibroblasts and many transformed cell lines. The gene for PAI-2 is modulated by many different stimuli (reviewed in 12). PAI-2 is a member of a sub-family of serpins, the ov-serpins, named for their archetypal member, ovalbumin (13). This family is characterized by a number of features, including the lack of a cleavable sequence to direct secretion through the ER-Golgi system; many of these proteins are therefore present predominantly as intracellular molecules. The location of PAI-2 appears to be cell-type specific, and endothelial cells and fibroblasts maintain PAI- 2 almost exclusively as an intracellular molecule, whereas monocytes have both intracellular and secreted PAI-2 (14-16). It is notable that when secretion does occur from monocytes, it does so by an ER-Golgi independent system, reminiscent of but not identical to that for interleukin $1 \beta$ (17). Dual location of PAI-2 may reflect different functions in the two sites. PAI-2 secreted by the monocyte efficiently modulates u-PA-mediated migration of cells (18), whereas intracellular PAI-2 has been shown to prevent cells from undergoing apoptosis; the mechanism for this inhibition is unknown (19-21). PAI-2 has a unique extended loop of 33 amino acids between helices $\mathrm{C}$ and $\mathrm{D}$. This loop is distant from the active site, and contains three glutamine residues that act as substrates for transglutaminases (22). This loop has been shown to be important for cross-linking of PAI-2 to trophoblast membranes and to Matrigel, a source of extracellular matrix (23). It has also been demonstrated that this interhelical loop is necessary for PAI-2 to inhibit apoptosis (21). PAI-2 has been shown to be cross-linked to structures within the cornified envelope of the epidermis, a thick deposit of protein that provides stability (24). Cross-linking is mediated by transglutaminases (TG), a ubiquitous family of enzymes that catalyze formation of a covalent amide bond between carboxyamide groups of donor glutamine residues and acyl acceptors of primary amines. The amino group of lysine residues serves as a common acyl acceptor (25). Specificity of crosslinking is determined by residues surrounding the glutamine, and also by the particular TG enzyme (26). The members of the TG family include factor XIII (FXIII) and tissue transglutaminse (TTG). FXIII in plasma, monocytes and platelets catalyses cross-linking of the fibrin clot, resulting in formation of a stable insoluble clot (25). FXIII inhibits fibrinolysis by cross-linking $\alpha_{2}$-antiplasmin $\left(\alpha_{2}-\mathrm{AP}\right)$ to fibrin. This reaction inhibits plasmin-mediated degradation of the fibrin clot (27). Tissue TG has a broad tissue distribution and is found in extracellular matrices (25), where TTG may play a role in ECM/fibrin stabilization (28). The other important situation where TTG plays a role is apoptosis, where increased TG activity delays the process of programmed cell death (25). In this investigation, we have demonstrated that activated peripheral blood monocytes secreted PAI-2, which was incorporated into an overlying fibrin clot. PAI-2 efficiently inhibited u-PAmediated fibrin clot lysis. PAI-2 was cross-linked to fibrin, in a 
transglutaminase-catalysed reaction that was dependent on glutamines 83 and 86. PAI-2 is an important inhibitor of u-PA-mediated fibrin lysis, and cross-linking of PAI-2 to fibrin may serve to localize its activity.

\section{Methods}

Isolation and culture of monocytes. Monocytes were isolated from human peripheral blood as previously described (16). Briefly, blood was collected, with informed consent, into $10 \% \mathrm{v} / \mathrm{v}$ of $3.8 \% \mathrm{w} / \mathrm{v}$ tri-sodium citrate. Blood was diluted with RPMI (Rosewell Park Memorial Institute) medium (Gibco BRL, UK) and layered onto Ficoll-paque (Pharmacia, UK). Blood samples were centrifuged, white blood cells were collected, and cells were washed three times with RPMI medium. The final cell pellet was resuspended in RPMI containing $10 \% \mathrm{v} / \mathrm{v}$ fetal calf serum (FCS), $2 \mathrm{mM}$ glutamine, $100 \mathrm{U} / \mathrm{ml}$ penicillin and $100 \mu \mathrm{g} / \mathrm{ml}$ streptomycin (RF10). Monocytes $\left(5 \times 10^{4}\right.$ monocytes/well) were isolated by preferential adherence to 96 -well plates (Nunc, UK) by incubation at $37^{\circ} \mathrm{C}$ for $1 \mathrm{~h}$ in a $5 \% \mathrm{CO}_{2}$ environment. Non-adherent cells were removed, monocytes were washed three times with RPMI, and monocytes were incubated for $18 \mathrm{~h}$ with $200 \mu \mathrm{l}$ per well of either RF10 or RF10 containing $10 \mathrm{ng} / \mathrm{ml}$ lipopolysaccharide (LPS). Endotoxin-free conditions were maintained throughout by the use of pyrogen-free disposable plasticware, solutions were sterilized through a $0.2 \mu \mathrm{m}$ filter, and endotoxin was monitored by the Limulus ameobocyte lysate assay (Sigma). The monocyte-rich population contained 90 to $95 \%$ monocytes, as monitored by the non-specific esterase stain.

Lactate dehydrogenase (LDH) was assayed as a measure of cell death using the CytoTox ${ }^{96}$ kit (Promega, UK), as previously described (16). Viability of cells was also studied using the Trypan blue membrane exclusion test.

Clot lysis assay on isolated monocytes. A microtitre plate fibrin clot lysis assay was performed on isolated monocytes (29). Monocytes were either untreated or stimulated with $10 \mathrm{ng} / \mathrm{ml}$ LPS for $18 \mathrm{~h}$, the conditioned medium $(200 \mu \mathrm{l})$ was removed, and stored for analysis at $-70^{\circ} \mathrm{C}$. Monocytes were washed twice with $171 \mathrm{mM} \mathrm{NaCl}, 3.4 \mathrm{mM} \mathrm{KCl}, 10.1 \mathrm{mM} \mathrm{Na}_{2} \mathrm{HPO}_{4}, 1.8 \mathrm{mM}$ $\mathrm{KH}_{2} \mathrm{PO}_{4}$ (PBS). Thrombin $(0.4 \mathrm{U} / \mathrm{ml})$ and calcium $(5.3 \mathrm{mM})$ were added to wells, and this was followed by fibrinogen $(2.94 \mu \mathrm{M}$, Kabi, Sweden) containing $0.24 \mu \mathrm{M}$ plasminogen in $10 \mathrm{mM}$ Tris, $0.88 \mathrm{mM} \mathrm{KCl}$ and $42.8 \mathrm{mM} \mathrm{NaCl}$, $\mathrm{pH} 7.4$, which resulted in a final volume of $100 \mu \mathrm{l} /$ well. Single chain t-PA ( $20 \mathrm{pM}$, Genentech, USA), two-chain t-PA from melanoma cells (20 pM, TNO Gaubius Institute, Netherlands) or u-PA (180 pM, NIBSC, UK) was added to the fibrinogen/plasminogen mixture. The microtitre plate was incubated at $37^{\circ} \mathrm{C}$ for $30 \mathrm{~min}$ to allow clot formation. Lysis of the fibrin clot was monitored by the decrease in turbidity $(405 \mathrm{~nm})$ and expressed as the time taken to achieve 50\% clot lysis. The involvement of monocyte PAI-2 or PAI-1 was studied by incorporation of $\mathrm{IgG}$ preparations of rabbit antibodies raised against PAI-2 (16), PAI-1 (30) or IgG from non-immune rabbit serum into the fibrin clot at a final concentration of $250 \mu \mathrm{g} / \mathrm{ml}$. The solubilized clots were collected at $8 \mathrm{~h}$ and stored at $-70^{\circ} \mathrm{C}$ for analysis, as were the monocytes, which were scraped from the microtitre plate into PBS. Experiments were performed on six occasions, on monocytes isolated from six individual donors, since donor variability between monocytes is a well-known phenomenon (16). Each condition was carried out in triplicate and data are shown from one experiment on a representative donor. Clot lysis in the absence of cells was assayed exactly as above. Recombinant PAI-1 (31) and rPAI-2 (32) (Delta Biotechnology, UK) were added as appropriate.

Preparation of human thrombi extracts. Extracts were prepared as previously described (6). Briefly, human thrombi were washed three times with $0.9 \% \mathrm{w} / \mathrm{v} \mathrm{NaCl}$, dried, fixed in $10 \%$ neutral buffered formalin and sectioned into $5 \mu \mathrm{m}$ pieces using a cryostat. Frozen samples were cut into small pieces and ground into a fine powder, using a Mikro-Dismembrator (B Braun Biotech, Melsungen, Germany) and liquid nitrogen. The sample was extracted in $50 \mathrm{mM}$ phosphate $\mathrm{pH}$ 7.0, 0.2 M epsilon amino-caproic acid, $1 \mathrm{M} \mathrm{NaCl}, 0.01 \%$ Tween 20, and was centrifuged at 11,600 g for $10 \mathrm{~min}$. The supernatant was removed and the pellet was re-extracted. A total of three extractions were assayed for PAI-2. PAI-2 antigen (ng/g tissue) was expressed as a sum of these three extractions. All samples were stored at $-70^{\circ} \mathrm{C}$.
Measurement of PAI-2. PAI-2 antigen was assayed in conditioned medium, clots, and monocytes by enzyme-linked immunosorbent assay (ELISA), as previously described (16). Briefly, microtitre plates (Costar, UK) were coated with a monoclonal antibody to PAI-2 (MAI-21, Biostat, UK; $2 \mu \mathrm{g} / \mathrm{ml}$ ). Recombinant PAI-2 (Delta Biotechnology) was diluted to give a standard curve of $0-10 \mathrm{ng} / \mathrm{ml}$. PAI-2 was detected using an IgG preparation of a rabbit antibody to $\mathrm{rPAI}-2$, and an antibody to rabbit IgG conjugated to alkaline phosphatase. Colour was generated by p-nitrophenol phosphate $(2 \mathrm{mg} / \mathrm{ml})$ in $0.1 \mathrm{M}$ glycine buffer, $\mathrm{pH} 10.4$, and absorbance was monitored at $405 \mathrm{~nm}$.

The activity of rPAI-2 and rPAI-1 was measured by inhibition of u-PAmediated cleavage of a chromogenic substrate, S-2444 (Chromogenix, UK) as described; the unit of inhibitor in each case was defined as that which inhibits 1 IU of u-PA (31). Activity of PAI-2 was also analyzed by fibrin zymography, following non-denaturing gel electrophoresis (33). Pregnancy plasma was run as a positive control for PAI-2 and was incubated with an antibody to $\alpha_{2}$-AP (Dako, UK) prior to electrophoresis.

Analysis of transglutaminase-catalyzed cross-linking. Fibrinogen $(1 \mu \mathrm{M}$, Kabi, Sweden) was diluted in PBS with or without addition of $200 \mathrm{nM} \mathrm{rPAI}-2$ (Delta Biotechnology, UK) or $200 \mathrm{nM} \alpha_{2}$-AP (Biopool, Sweden). Purified guinea pig liver transglutaminase (Sigma, UK) or human plasma FXIIIA (American Diagnostica, USA) was added to the clots at final concentrations of $200 \mathrm{nM}$ or $400 \mathrm{nM}$. Fibrin formation was initiated by addition of bovine thrombin $(0.4 \mathrm{U} / \mathrm{ml})$ and $2.5 \mathrm{mM} \mathrm{CaCl}_{2}$. Inhibition of transglutaminase activity was achieved by addition of either $200 \mathrm{nM}$ Tridegin (34) (Biopharm UK Ltd), $10 \mathrm{mM}$ EDTA or $80 \mathrm{mM}$ iodoacetamide (IAA), prior to addition of transglutaminases. Peptides were synthesized in-house and were incorporated into clots at a final concentration of $20 \mu \mathrm{M}$. The sequences of the peptides were as follows -

Peptide 1 Gly-Phe-Met-Gln-Gln-Ile-Gln-Lys-Gly-Ser Peptide 2 Gly-Phe-Met-Ser-Ser-Ile-Ser-Lys-Gly-Ser Peptide 3 Gly-Phe-Met-Gln-Ser-Ile-Ser-Lys-Gly-Ser Peptide 4 Gly-Phe-Met-Ser-Gln-Ile-Ser-Lys-Gly-Ser Peptide 5 Gly-Phe-Met-Ser-Ser-Ile-Gln-Lys-Gly-Ser.

Clots were incubated at $37^{\circ} \mathrm{C}$ for $1 \mathrm{~h}$, and were then solubilized with an equal volume of $8 \mathrm{M}$ urea, $200 \mathrm{mM}$ Tris, $4 \% \mathrm{w} / \mathrm{v}$ SDS, $40 \mathrm{mM}$ dithiothreiterol for $30 \mathrm{~min}$ at $37^{\circ} \mathrm{C}$. These samples were analyzed by SDS-PAGE on 3-12\% acrylamide gels. Proteins were transferred overnight to nitrocellulose membrane (Bio-Blot-NC, Costar, UK) and immunoblotted for either PAI-2 or $\alpha_{2}$-AP. Membranes were blocked with $50 \mathrm{mM}$ carbonate/bicarbonate buffer $\mathrm{pH} 9.6$ containing $3 \% \mathrm{w} / \mathrm{v}$ bovine serum albumin. Antigen was detected using a mouse monoclonal antibody to PAI-2 (Biostat, UK) or a rabbit antibody to $\alpha_{2}$-AP (Dako, UK), followed by either anti-mouse or anti-rabbit IgG preparation conjugated to alkaline phosphatase. Colour was detected using $200 \mathrm{mM}$ Tris/ $\mathrm{HCl}, 10 \mathrm{mM} \mathrm{MgCl}_{2}$, pH 9.5 containing $0.6 \mathrm{mM}$ 5'-bromo 4-chloro 3-iodophosphate and $0.5 \mathrm{mM}$ nitroblue tetrazolium.

Immunoprecipitation of fibrin clots was carried out by addition of $500 \mu \mathrm{l}$ $50 \mathrm{mM}$ Tris/ $\mathrm{HCl}, \mathrm{pH} 8.0,500 \mathrm{mM} \mathrm{NaCl}, 50 \mathrm{mM}$ EDTA, $1 \%$ Tween 20 (NET buffer) to disperse the fibrin clot. A mouse monoclonal antibody to fibrin (35) was incubated with samples for $90 \mathrm{~min}$, and 50\% v/v protein A Sepharose in NET buffer was rotated at $4^{\circ} \mathrm{C}$ for $90 \mathrm{~min}$. Centrifugation was employed to collect the antibody-antigen-Sepharose bead complex, and the beads were washed twice with NET buffer and twice with $10 \mathrm{mM}$ Tris, $\mathrm{pH}$ 6.8. The Sepharose beads were incubated in $8 \mathrm{M}$ urea, $200 \mathrm{mM}$ Tris, $4 \% \mathrm{w} / \mathrm{v}$ SDS, $40 \mathrm{mM}$ dithiothreiterol, and electrophoresed on 3-12\% gradient acrylamide gels as above. PAI-2 antigen, cross-linked to the fibrin, was detected using a rabbit $\operatorname{IgG}$ to PAI-2 (16). Colour was developed as above.

\section{Results}

Inhibition of fibrin clot lysis by recombinant PAI-2. The effect of recombinant PAI-2 on fibrin clot lysis was analyzed using a functional assay. Clots were formed from purified plasminogen and fibrinogen by addition of thrombin and calcium. Lysis was induced using either u-PA 


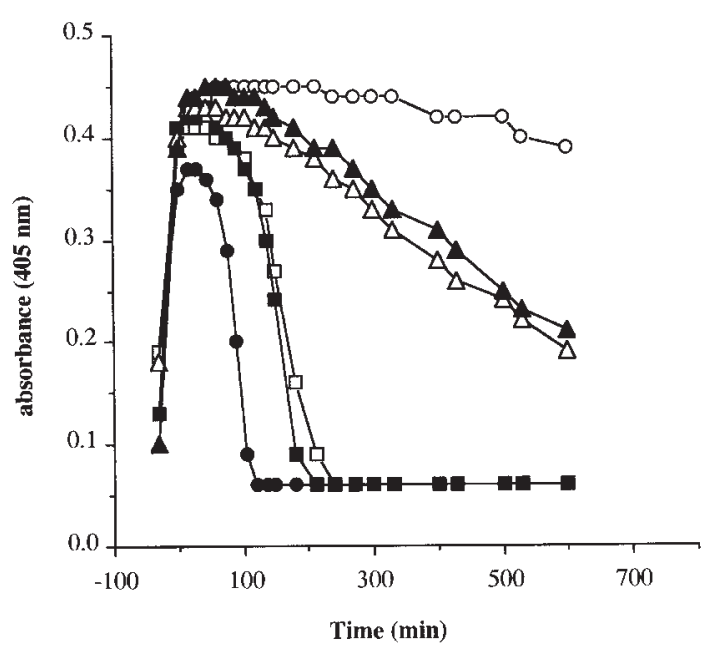

Fig. 1 Inhibition of u-PA-mediated clot lysis by rPAI-2 and rPAI-1. Fibrin clots were allowed to form in a microtitre plate by incubation of $2.94 \mu \mathrm{M}$ fibrinogen, $0.24 \mu \mathrm{M}$ plasminogen in the presence of $0.4 \mathrm{U} / \mathrm{ml}$ thrombin and $5.3 \mathrm{mM}$ $\mathrm{CaCl}_{2}$. No u-PA $(\bigcirc)$ or $180 \mathrm{pM} \mathrm{u-PA}(\bigcirc)$ was added to the clots. The inhibitory effect of $60 \mathrm{mU} /$ well rPAI-1 ( $\square), 60 \mathrm{mU}$ rPAI-2 (ם), $120 \mathrm{mU}$ rPAI-1 ( $\triangle$ ) and $120 \mathrm{mU}$ rPAI-2 (A) was monitored by turbidity at $405 \mathrm{~nm}$

$(180 \mathrm{pM})$ or t-PA $(20 \mathrm{pM})$, and the effect of recombinant PAI-2 on lysis was studied. Recombinant PAI-2, and PAI-1 for comparison, were used at 30,60,120, and $180 \mathrm{mU} /$ well, the unit of activity being defined by inhibition of u-PA-mediated cleavage of the chromogenic substrate, S-2444 (31). The inhibitory effect of PAI-2 and PAI-1, at 60 and $120 \mathrm{mU} /$ well, on u-PA-mediated clot lysis is shown (Fig. 1). Both PAI-2 and PAI-1 showed a dose-dependent inhibition of lysis. Importantly, PAI-2 was as efficient as PAI-1 in this assay; this was true for all concentrations of PAI-2 and PAI-1 studied. The time for $50 \%$ clot lysis on addition of u-PA was 80 min. This time was increased to $110 \mathrm{~min}$ in the presence of $30 \mathrm{mU}$ PAI-2 and PAI-1, and $170 \mathrm{~min}$ and $180 \mathrm{~min}$ in the presence of $60 \mathrm{mU}$ PAI-2 and $60 \mathrm{mU}$ PAI-1, respectively. Addition of $120 \mathrm{mU}$ PAI-2 and $120 \mathrm{mU}$ PAI-1 increased the time for $50 \%$ lysis to $510 \mathrm{~min}$ and $530 \mathrm{~min}$, while it was greater than $700 \mathrm{~min}$ on addition of $180 \mathrm{mU}$ PAI. PAI-2 did not inhibit either singlechain or two-chain t-PA-mediated clot lysis, even at elevated concentrations of $2 \mu \mathrm{M}$ PAI-2, but PAI-1 inhibited t-PA induced lysis in a dose-dependent manner (data not shown).

Inhibition of fibrin clot lysis by cellular PAI-2. The effective inhibition of u-PA-induced fibrin clot lysis by recombinant PAI-2 was extended to investigate a cellular source of PAI-2. Human peripheral blood monocytes were studied, activated monocytes being an abundant source of PAI-2 (16). Isolated monocytes were either untreated or stimulated with lipopolysaccharide (LPS), which up-regulates both secreted and intracellular forms of PAI-2. Conditioned medium was removed after $18 \mathrm{~h}$ incubation, and monocytes were overlaid with a fibrin clot. Monocytes inhibited u-PA- but not t-PA-induced fibrin clot lysis (Fig. 2A). This inhibition was only seen with activated monocytes, which correlated with an up-regulation in the synthesis of PAI-2. The time for $50 \%$ lysis of the clot by t-PA $(20 \mathrm{pM})$ was $50 \mathrm{~min}$ in the presence of unstimulated and LPS-stimulated monocytes. U-PA-mediated clot lysis (180 pM NIBSC u-PA) showed a half lysis time of $100 \mathrm{~min}$ in the presence of unstimulated monocytes, which increased to $340 \mathrm{~min}$ following LPS-stimulation. This increase in lysis time was due to PAI-2, since antibodies to PAI-2 neutralized the inhibitory effect (Fig. 2B). In contrast, antibodies to PAI-1 (Fig. 2B) or normal rabbit
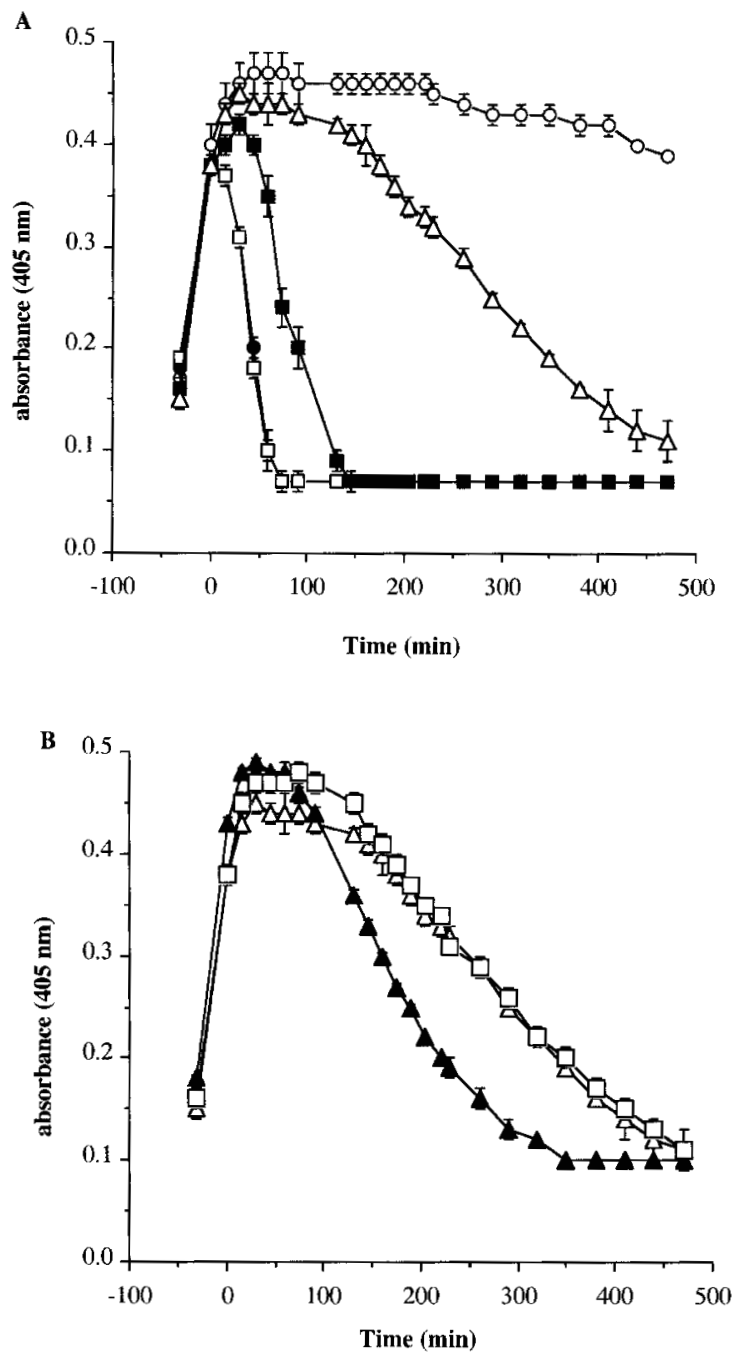

Fig. 2 Peripheral blood monocytes inhibit u-PA-mediated clot lysis. A) Isolated monocytes were either untreated or treated with LPS (10 ng/ml) for $18 \mathrm{~h}$. Conditioned medium was removed, and monocytes were overlaid with $2.94 \mu \mathrm{M}$ fibrinogen, $0.24 \mu \mathrm{M}$ plasminogen, $0.4 \mathrm{U} / \mathrm{ml}$ thrombin and $5.3 \mathrm{mM}$ $\mathrm{CaCl}_{2}$. The effect of untreated $(\bigcirc)$ or LPS-treated $(\square)$ monocytes on lysis by t-PA $(20 \mathrm{pM})$, and the effect of untreated $(\mathbf{\square})$ or LPS-treated $(\triangle)$ monocytes on lysis by u-PA $(180 \mathrm{pM})$ was investigated. Monocytes were also overlaid with fibrin clots containing no added t-PA or u-PA $(O)$. Values represent mean \pm $\mathrm{SEM}$, from triplicate wells of monocytes from a representative donor, the experiment being typical of a total of six. B) The inhibitory effect of LPStreated monocytes on fibrin lysis by u-PA $(180 \mathrm{pM})$ was investigated further. Fibrin clots contained $250 \mu \mathrm{g} / \mathrm{ml}$ rabbit IgG to PAI-1 ( $\square$ ), to PAI-2 ( $\mathbf{\Delta})$ or no antibody $(\triangle)$. Values represent mean \pm SEM, from triplicate wells of monocytes from a representative donor, typical of 6 experiments

IgG (data not shown) had no effect on clot lysis. The addition of antibodies to PAI-1 or PAI-2 had no effect on clot lysis by unstimulated monocytes. The data shown here represent monocytes isolated from one donor, since variability is seen between monocyte populations (16). Inhibition of clot lysis by activated monocytes was reproducible on five further occasions. In all cases, activated monocytes inhibited only u-PA-induced lysis and not t-PA-mediated clot lysis, and antibodies to PAI-2 neutralized the inhibitory effect.

Inhibition of fibrin clot lysis by monocyte-derived PAI-2 demonstrated that monocytes had secreted PAI-2, which had penetrated the overlying clot. PAI-2 antigen was analyzed by ELISA in the condi- 


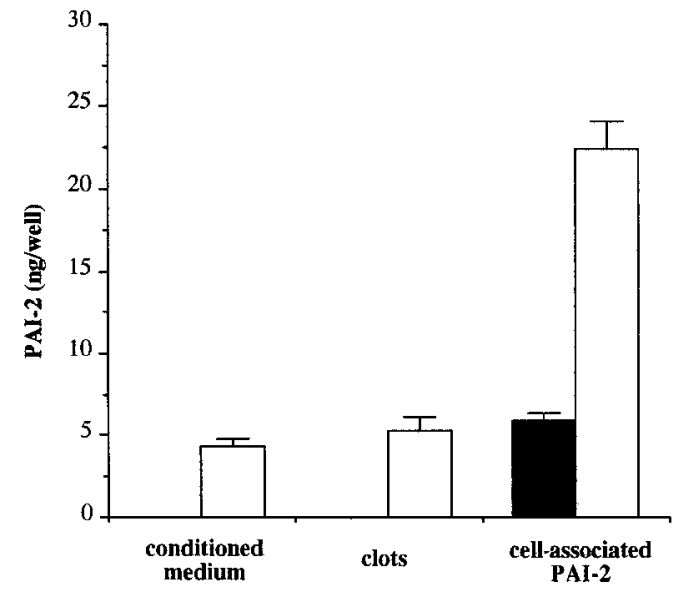

Fig. 3 PAI-2 is secreted by monocytes into the fibrin clot. Isolated monocytes were either untreated ( $\mathbf{\square})$ or LPS-treated $(\square)$ for $18 \mathrm{~h}$. Conditioned medium was removed and monocytes were overlaid with $2.94 \mu \mathrm{M}$ fibrinogen, $0.24 \mu \mathrm{M}$ plasminogen, $0.4 \mathrm{U} / \mathrm{ml}$ thrombin and $5.3 \mathrm{mM} \mathrm{CaCl}_{2}$. Lysis of clots was induced by addition of $180 \mathrm{pM} \mathrm{u}$-PA, and absorbance at $405 \mathrm{~nm}$ was monitored. The solubilized clots were removed from monocytes, and monocytes were scraped from the microtitre well. PAI-2 (ng/well) was analyzed by ELISA in conditioned medium, in solubilized clots and in monocyte lysates. Values represent mean \pm SEM, from triplicate wells of monocytes from a representative donor, typical of 6 experiments

tioned medium that had been removed prior to the assay, in the solubilized clot, and in the cells that had been scraped from the microtitre plate following the assay. PAI-2 antigen in the conditioned medium of LPStreated monocytes reached a concentration of $3.8 \mathrm{ng} /$ well following $18 \mathrm{~h}$ incubation, and was not detected in the conditioned medium of unstimulated cells (Fig. 3). Similarly, PAI-2 was detectable only in the clots that had been removed from LPS-stimulated monocytes, where it was present at $5.3 \mathrm{ng} /$ well. Cell-associated PAI-2 was detected at higher levels. Unstimulated cells accumulated PAI-2 at $5.9 \mathrm{ng} / \mathrm{well}$, which increased to $22.4 \mathrm{ng} /$ well on LPS treatment. Cell-associated PAI-2 remained the biggest pool over the time course of the clot lysis assay, some $8 \mathrm{~h}$, but a considerable amount (approximately 25\%) of PAI-2 was secreted into the clot, where it efficiently inhibited clot lysis. The fibrin clots were also assayed for lactate dehydrogenase (LDH) by colorimetric assay, to evaluate whether the monocytes had undergone cell death, releasing PAI-2 into the fibrin clot. This was not the case, since LDH was not detectable in the solubilized fibrin clot. The clots were also analyzed for the presence of cells by the Trypan blue membrane exclusion stain and microscopy. No monocytes were evident, showing that the cells had not become detached from the tissue culture plate.

PAI-2 is present in human thrombi. Extracts from arterial and venous human thrombi were also examined for the presence of active PAI-2 by fibrin zymography following non-denaturing gel electrophoresis. A zone of inhibitory activity (Fig. 4, track A) was seen in both arterial and venous thrombus extracts. This inhibitory activity was demonstrated to be PAI-2, since only antibodies to PAI-2 neutralized the inhibitory zone (Fig. 4, track D). Antibodies to PAI-1 (Fig. 4, track B), or $\alpha_{2}$-AP (Fig. 4, track C) had no effect. The extract was also incubated with all three antibodies (Track E), and pregnancy plasma was used as a positive control for PAI-2 activity (Track F). PAI-2 antigen was extractable from thrombi over a wide range, $0-87 \mathrm{ng} / \mathrm{g}$ tissue, and there was no clear difference between the venous and arterial thrombi in this respect.
Cross-linking of PAI-2 to fibrin by transglutaminases. We investigated whether PAI-2 could be cross-linked to fibrin, and analyzed this phenomenon in a purified system using TTG and FXIII. $\alpha_{2}$-AP is known to be cross-linked to fibrin, in a reaction that is catalyzed by activated FXIII (27), and this was included for comparison. Fibrinogen was clotted by addition of thrombin and calcium chloride, in the presence of recombinant PAI-2 or $\alpha_{2}$-AP and purified TTG or purified FXIII. The formation of cross-linked higher molecular mass species of PAI- $2 / \alpha_{2}$-AP was assessed by SDS-PAGE on 3 to $12 \%$ acrylamide gradient gels (mini or maxi gels) and western blotting.

PAI-2 was cross-linked to fibrin and formed higher molecular mass forms of PAI-2 (Fig. 5A). Cross-linking was achieved by either TTG or FXIIIA, in a dose-dependent manner. The cross-linked forms of PAI-2 were observed at a variety of molecular masses, all greater than $120 \mathrm{kDa}$ (tracks e-h); no PAI-2 was detectable in the stacking gel. Some differences were observed depending on whether TTG or FXIII was used. The formation of these cross-linked products was dependent on the presence of transglutaminase and calcium. It is known that PAI-2 can cross-link/polymerize to itself (23). The use of gradient gels clearly distinguished between cross-linking of PAI-2 to fibrin and cross-linking/polymerization of PAI-2 to itself (note the diffuse band of about $90 \mathrm{kDa}$ in track a-c). Distinct high molecular mass forms of PAI-2 were found only in the presence of fibrin and TG, traces of these bands in track d suggesting that the fibrinogen used was contaminated with FXIII. The intense high molecular mass bands seen in tracks e-h were confirmed as representing PAI-2 cross-linked to fibrin by immunoprecipitation of clots with a monoclonal antibody to fibrin (35) and immunoblotting with antibodies to PAI-2 (data not shown). Crosslinking of $\alpha_{2}$-AP to fibrin was also achieved by TTG or FXIIIA (Fig. 5B). In contrast, rPAI-1 was not cross-linked to fibrin (data not shown).

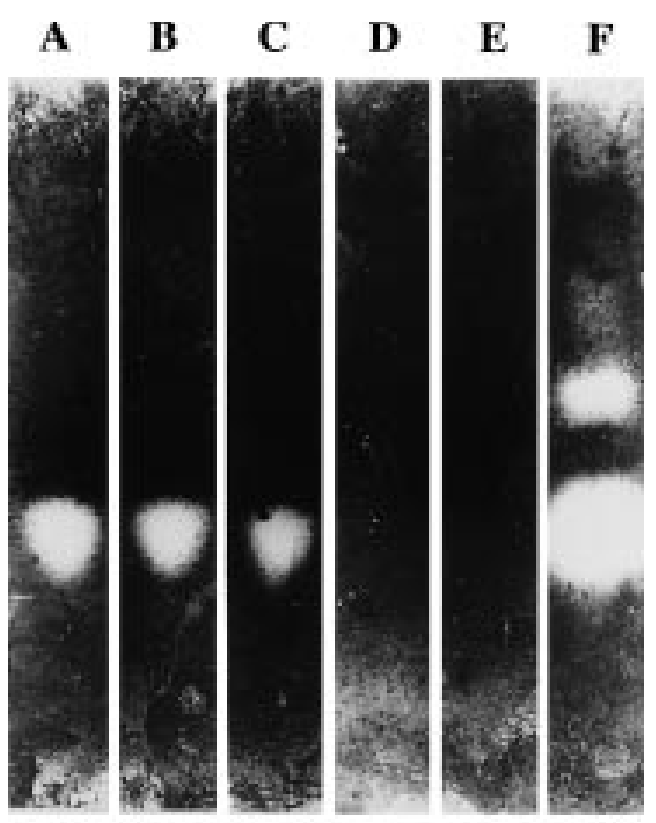

Fig. 4 PAI-2 is present in human thrombi. Extracts of arterial and venous human thrombi were made. The extract (30 $\mu \mathrm{l}$ per track) was incubated with $100 \mu \mathrm{g}$ pre-immune rabbit IgG (A), rabbit IgG to PAI-1 (B), rabbit IgG to $\alpha_{2}$ AP (C), rabbit IgG to PAI-2 (D) or $100 \mu \mathrm{g}$ of each antibody (E). Pregnancy plasma was incubated with the rabbit IgG to $\alpha_{2}-\mathrm{AP}(\mathrm{F})$. Samples were run on a non-denaturing gel, and the gels were overlaid on a fibrin plates, which were lysed with u-PA $(0.05 \mathrm{IU} / \mathrm{ml})$ 

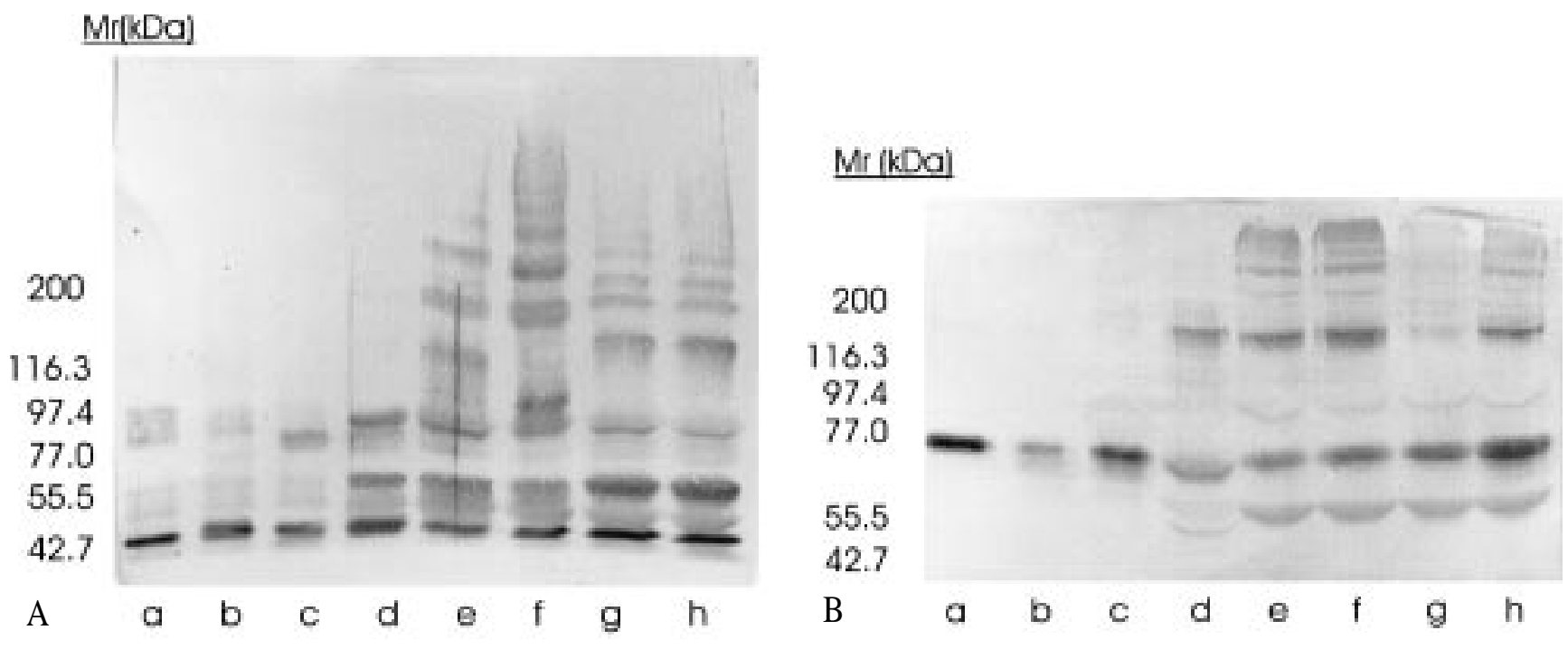

Fig. 5 Cross-linking of PAI-2 and $\alpha_{2}$-AP to fibrin. The effect of TTG and FXIIIA on cross-linking of PAI-2 (A) and $\alpha_{2}$-AP (B) was studied in a purified system containing either fibrinogen $(1 \mu \mathrm{M}), 0.4 \mathrm{U} / \mathrm{ml}$ thrombin, $2.5 \mathrm{mM} \mathrm{CaCl}, 200 / 400 \mathrm{nM}$ TTG, or 200/400 nM FXIIIA. Samples were incubated for $1 \mathrm{~h}$ at $37^{\circ} \mathrm{C}$ and clots were analyzed by SDS-PAGE on 3-12\% acrylamide mini gels, followed by western blotting with antibodies to PAI-2 or $\alpha_{2}-\mathrm{AP}$. PAI- $2 / \alpha_{2}$-AP (200 nM), were incubated for $1 \mathrm{~h}$ at $37^{\circ} \mathrm{C}$ with additions as follows: (a) no addition, (b) $200 \mathrm{nM} \mathrm{TTG}$, thrombin and $\mathrm{CaCl}_{2}$, (c) $200 \mathrm{nM} \mathrm{FXIIIA,} \mathrm{thrombin} \mathrm{and} \mathrm{CaCl}$, (d) fibringen, thrombin and $\mathrm{CaCl}_{2}$, (e) fibrinogen, $200 \mathrm{nM} \mathrm{TTG}$, thrombin and $\mathrm{CaCl}_{2}$, (f) fibrinogen, $400 \mathrm{nM} \mathrm{TTG}$, thrombin and CaCl 2 , (g) fibrinogen, $200 \mathrm{nM}$ FXIIIA, thrombin and $\mathrm{CaCl}_{2}$, (h) fibrinogen, $400 \mathrm{nM}$ FXIIIA, thrombin and $\mathrm{CaCl}_{2}$

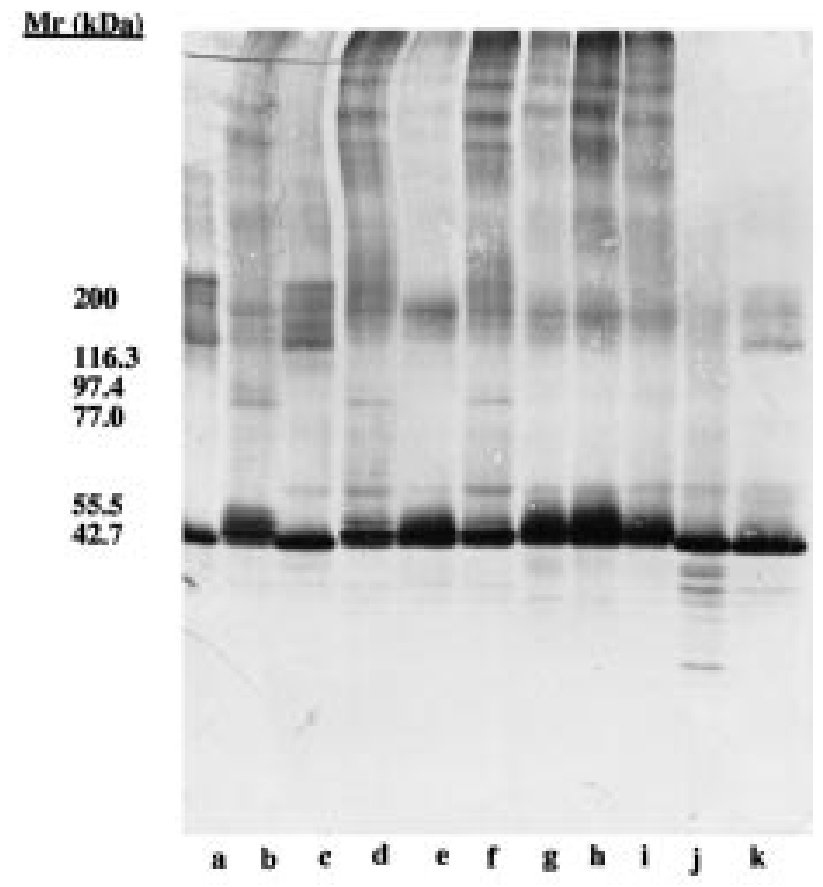

Fig. 6 Mechanism for cross-linking of PAI-2 to fibrin. PAI-2 $(200 \mathrm{nM})$ was incubated alone (a) or in the presence of $200 \mathrm{nM}$ TTG and $2.5 \mathrm{mM} \mathrm{CaCl}_{2}$ (b). Cross-linking of PAI-2 $(200 \mathrm{nM})$ to fibrin was studied as follows in the presence of fibrinogen $(1 \mu \mathrm{M}), 0.4 \mathrm{U} / \mathrm{ml}$ thrombin, $2.5 \mathrm{mM} \mathrm{CaCl}_{2}$ for $1 \mathrm{~h}$ at $37^{\circ} \mathrm{C}$. Samples were analyzed by SDS-PAGE on $12 \%$ acrylamide maxi gels and western blotting for PAI-2. (c) no further addition, (d) with $200 \mathrm{nM}$ TTG, (e) with $200 \mathrm{nM}$ TTG and $20 \mu \mathrm{M}$ peptide 1 (QQIQ), (f) with $200 \mathrm{nM}$ TTG and $20 \mu \mathrm{M}$ peptide 2 (SSIS), (g) with $200 \mathrm{nM}$ TTG and $20 \mu \mathrm{M}$ peptide 3 (QSIS), (h) with $200 \mathrm{nM}$ TTG and $20 \mu \mathrm{M}$ peptide 4 (SQIS), (i) with $200 \mathrm{nM}$ TTG and $20 \mu \mathrm{M}$ peptide 5 (SSIQ), (j) with $200 \mathrm{nM}$ TTG and $200 \mathrm{nM}$ Tridegin, (k) with $200 \mathrm{nM}$ TTG and $10 \mathrm{mM}$ EDTA
Mechanism of cross-linking of PAI-2 to fibrin. The mechanism of cross-linking of PAI-2 to fibrin was investigated by studying the involvement of residues 80-90, and in particular the role of Gln 83, 84 and 86 , by incorporation of peptides into the cross-linking reaction. Peptide 1 contained all three glutamine residues, and peptide 2 had all glutamine residues replaced by serine residues. Peptides 3 to 5 contained only one glutamine, glutamine 83 or 84 or 86 , respectively. Peptide 1 inhibited cross-linking of PAI-2 to fibrin, competing with the cross-linking site on PAI-2 (Fig. 6, track e). Peptide 2, with no glutamines, acted as a control peptide, and had no effect on cross-linking of PAI-2 to fibrin (track f). Peptide 3, which contained glutamine 83, inhibited cross-linking (track g). In contrast, glutamine 84 did not affect cross-linking of PAI-2 to fibrin (peptide 4, track h). Glutamine 86 was also involved in cross-linking, since peptide 5 competed for crosslinking of PAI-2 (track i). This demonstrated that glutamines 83 and 86 are important for cross-linking of PAI-2 to fibrin, but inhibition of cross-linking was most effective in the presence of the peptide containing all three glutamine residues.

The dependence of cross-linking on transglutaminase activity was investigated using Tridegin, which is a specific inhibitor of activated FXIII and tissue TG. Tridegin has been isolated from the leech, Haementeria ghilianii (34) and was kindly supplied by Biopharm UK Ltd. Tridegin was incorporated into the system at the same final molar concentration as transglutaminases $(200 \mathrm{nM})$. Tridegin inhibited crosslinking of PAI-2 to fibrin (Fig. 6, track j). Transglutaminases require an active-site cysteine residue and calcium for activity, and therefore general inhibition of TG can be achieved by the use of alkylating and chelating agents, IAA and EDTA respectively. Both IAA (data not shown) and EDTA (Fig. 6, track k) inhibited cross-linking as did Tridegin (Fig. 6). Cross-linking of $\alpha_{2}$-AP to fibrin was similarly inhibited by Tridegin, IAA and EDTA (data not shown). 
Effect of cross-linking on activity of PAI-2. We have shown that rPAI-2 was cross-linked to fibrin and that monocyte-derived PAI-2 efficiently inhibited fibrin clot lysis. This was extended by studying the effect of cross-linking on activity of rPAI-2, using the purified system, in which $200 \mathrm{nM}$ TTG was added to fibrin in the presence and absence of rPAI-2 at 60, 120, and $180 \mathrm{mU} /$ well. Addition of TTG had no effect on u-PA-mediated clot lysis, and the time for half lysis was $100 \mathrm{~min}$ whether or not TTG was present (Fig. 7). PAI-2 (60 mU/well) inhibited clot lysis and the time for half lysis was increased to $250 \mathrm{~min}$. No effect of TTG was seen and the time for half lysis remained at $250 \mathrm{~min}$, showing that cross-linking did not affect the activity of rPAI-2. Addition of TTG similarly had no effect on the inhibitory activity of rPAI-2 at 120 or $180 \mathrm{mU} /$ well (data not shown). Further support for the retention of PAI-2 activity after cross-linking comes from assay of PAI-2 inhibition of u-PA, measured with the chromogenic substrate S2444. We found no effect on PAI-2 activity following the inclusion of TTG or FXIII in the presence of fibrin or fibrinogen (data not shown).

Monocytes were overlaid with fibrin clots, which were subsequently analyzed for activity of PAI-2, by fibrin zymography following nondenaturing gel electrophoresis, a semi-quantitative technique (33). The activity of PAI-2 in the clots was compared to the activity of PAI-2 in conditioned medium of monocytes and in pregnancy plasma, which has been previously studied (36). Equivalent amounts of PAI-2 antigen $(2 \mathrm{ng})$ from conditioned medium and fibrin clots were electrophoresed, and both sources of PAI-2 were equally active (Fig. 8). PAI-2 in conditioned medium electrophoresed alongside the fast migrating band of PAI-2 seen in pregnancy plasma. These inhibitory bands were shown to be PAI-2 by incorporation of a rabbit antibody to PAI-2, which neutralized activity (data not shown). It was interesting to note that monocytederived PAI-2 in the fibrin clot migrated slightly differently to PAI-2 in conditioned medium and pregnancy plasma. It was also strikingly efficient in inhibiting clot lysis, such that the gel had to be incubated for an additional $24 \mathrm{~h}$ for the opaque zone to become clear, by which time the slow band of PAI-2 in pregnancy plasma had almost disappeared.

\section{Disc ussion}

This study has shown that monocyte PAI-2 retains activity after being cross-linked to fibrin by the two major transglutaminases, tissue TG and FXIII. PAI-2 is the second serpin that is localized to the fibrin surface in this manner, the well-known example being $\alpha_{2}$-AP (26). In this situation, monocyte PAI-2 acts as an efficient inhibitor of u-PAmediated fibrin clot lysis.

Both recombinant PAI-2 and monocyte-derived PAI-2 effectively inhibited u-PA-mediated fibrin clot lysis, whereas it had no effect on t-PA. This agrees with a previous report that fibrin-bound t-PA, but not poly-D-lysine-stimulated t-PA, was resistant to inactivation by minactivin (PAI-2) (37). The lack of inhibition of t-PA may reflect protection of t-PA activity by fibrin (37). In the absence of fibrin, PAI-2 can inhibit two-chain t-PA (12), whereas in this study it had no effect on either single-chain or two-chain t-PA. In contrast, its inhibition of u-PA was comparable to that of PAI-1, over the time course of a fibrin clot lysis assay, despite its being an order of magnitude poorer an inhibitor of u-PA on the basis of its second order rate constant (12).

The inhibition of u-PA by PAI- 2 argues for a role for PAI- 2 in local environments and the association of $\mathrm{u}-\mathrm{PA}$ and PAI-2 with cell-associated fibrinolysis (18). u-PA has been implicated in migration of cells and extracellular matrix remodelling, and u-PA binds to its cellular receptor, u-PAR (39). Accumulation of u-PA in the diseased vessel wall has been shown in studies in the mouse and human $(40,5)$. There-

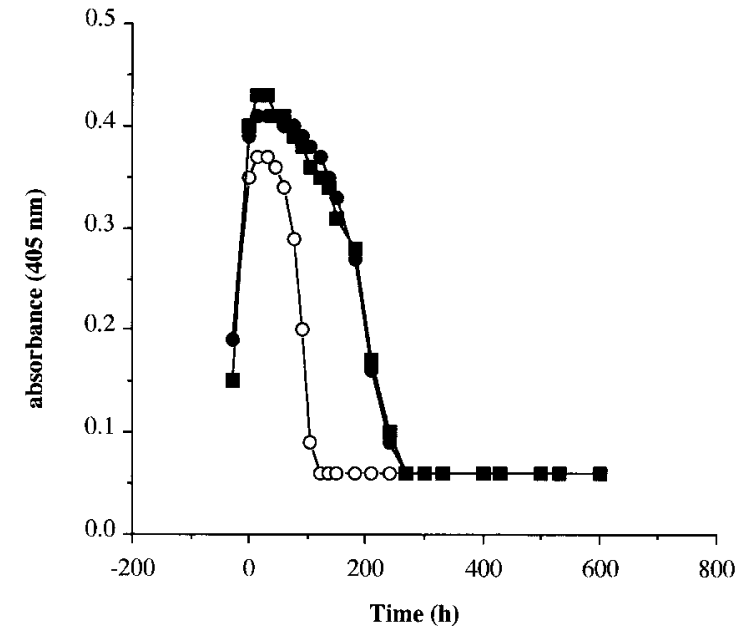

Fig. 7 Effect of transglutaminase on activity of PAI-2. Fibrin clots were allowed to form in a microtitre plate by incubation of $2.94 \mu \mathrm{M}$ fibrinogen, $0.24 \mu \mathrm{M}$ plasminogen in the presence of $0.4 \mathrm{U} / \mathrm{ml}$ thrombin and $5.3 \mathrm{mM} \mathrm{CaCl}_{2}$. Lysis was achieved by addition of $180 \mathrm{pM} \mathrm{u}-\mathrm{PA}(\mathrm{O})$. The inhibitory effect of $60 \mathrm{mU} / \mathrm{well} \mathrm{rPAI}-2 \mathrm{O}$ ) and $60 \mathrm{mU} /$ well rPAI-2 in the presence of $200 \mathrm{nM}$ TTG (ם) was investigated by monitoring the absorbance at $405 \mathrm{~nm}$

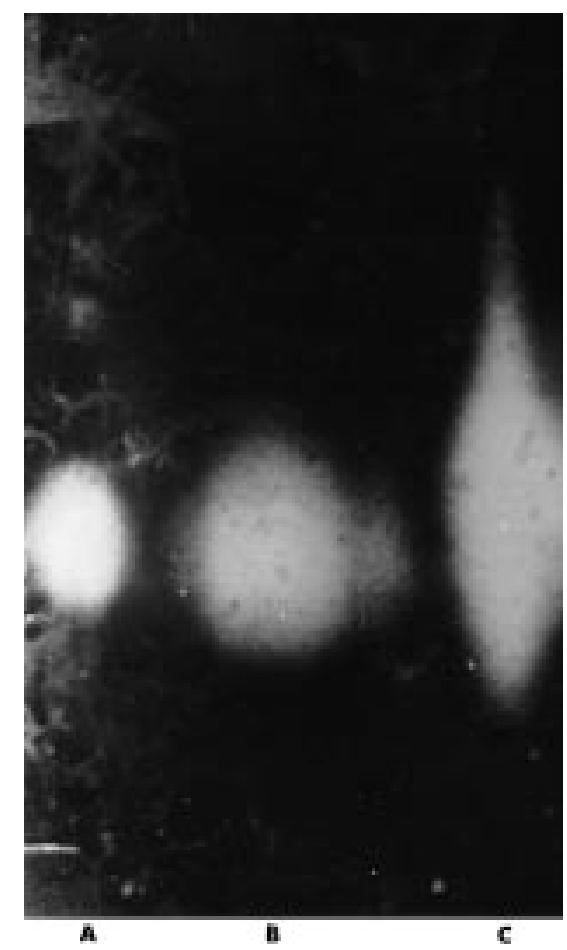

Fig. 8 Activity of PAI-2 secreted by monocytes into fibrin clot. Isolated monocytes were treated with $10 \mathrm{ng} / \mathrm{ml}$ LPS for $18 \mathrm{~h}$ and the conditioned medium was removed. Monocytes were overlaid with $2.94 \mu \mathrm{M}$ fibrinogen, $0.24 \mu \mathrm{M}$ plasminogen, $0.4 \mathrm{U} / \mathrm{ml}$ thrombin and $5.3 \mathrm{mM} \mathrm{CaCl}_{2}$ and lysis was induced by addition of $180 \mathrm{pM}$ u-PA. Solubilized clots were collected. Samples of conditioned medium (B) and clot (C), corresponding to 2 ng PAI-2 measured by ELISA, was run on non-denaturing gels and activity of PAI-2 was analyzed by fibrin zymography. Pregnancy plasma was run as a positive control for PAI-2 (A) 
fore, PAI-2 is likely to contribute to persistence of fibrin in environments such as the atherosclerotic plaque. It has recently been observed that PAI-2 antigen is indeed present within the vessel wall (7). Here, we demonstrate the presence of active PAI-2 in extracts of human thrombi, which suggests that PAI-2 may also have a role in protecting thrombi from dissolution. PAI-2 antigen was extractable from both arterial and venous thrombi, ranging from 0 to $87 \mathrm{ng} / \mathrm{g}$ of tissue. There was no correlation between the concentration of PAI- 2 and the source of the thrombus, whether arterial or venous. It is possible that only a proportion of the thrombus PAI-2 was extractable as a result of the crosslinking that this study demonstrates. In contrast, PAI-1 antigen was extractable from the same thrombi in the range of 40-7700 ng/g tissue (6). The cellular source of PAI-2 in the thrombus is as yet unknown, but it is possible that activated monocytes secrete active PAI- 2 into the thrombus.

Cross-linking of PAI-2 to fibrin was achieved by TTG or activated FXIII. These two enzymes show different specificities, with TTG preferentially mediating cross-linking of the $\alpha$-chains of fibrinogen, whereas activated FXIII cross-links $\gamma$-chains (28). The distribution of TTG and FXIII is different, and TTG is constitutively expressed by endothelial cells, macrophages; expression of TTG is elevated during wound healing (41). FXIII is found in plasma at $700 \mathrm{nM}$ and is also detected in monocytes and platelets, which allows localization of FXIII at the site of thrombus formation (25). Cross-linking of PAI-2 to fibrin was compared with that of $\alpha_{2}$-AP, since this inhibitor plays a significant role in protection of a fibrin clot from lysis (27). Both FXIII and TTG catalyse cross-linking of $\alpha_{2}$-AP to the $\alpha$-chain of fibrinogen, via a glutamine residue at the N-terminus of $\alpha_{2}$-AP (42). Cross-linking of PAI-2 to fibrin did not affect the activity of PAI-2, in agreement with data on PAI-2 cross-linked to cellular membranes (23). The loop that contains glutamine residues 83,84 and 86 is distant from the reactive centre (22), consistent with the lack of effect of cross-linking on activity. PAI-2 that was secreted by monocytes into an overlying clot was also active. It is not yet known if this material was cross-linked, but it was interesting to note that PAI-2 from the fibrin clot migrated differently to PAI-2 in conditioned medium or in pregnancy plasma. Monocytes can synthesize both TTG and FXIII; these cells have secreted and intracellular pools of both enzymes (25).

PAI-2 was found to cross-link to fibrin via glutamine residues present on the interhelical loop (residues 66 to 98) and we demonstrated that not every glutamine residue played an equal role as a donor in the cross-linking reaction. Competition by peptides showed that glutamines 83 and 86 were important in cross-linking, glutamine 83 being the principal residue involved. Glutamine 84 did not appear to be necessary, perhaps reflecting steric hindrance and proximity to glutamine 83 . It is interesting that glutamines 83 and 86 are conserved in PAI-2 from other species, for instance in rat (22).

Cross-linking of both PAI- 2 and $\alpha_{2}$-AP was inhibited by Tridegin, a novel specific inhibitor of FXIII and TTG isolated from the leech (34). Tridegin and hirudin, a specific inhibitor of thrombin (43), inhibit fibrin clot cross-linking and fibrin clot formation, respectively, which presumably allows the leech to feed easily on host blood. Tridegin has been found to enhance fibrinolysis by inhibition of cross-linking between fibrin strands (44). Tridegin was a useful inhibitor of transglutaminase activity, and gave similar results to inhibition by the general inhibitors of TG, iodoacetamide and EDTA (25).

Monocytes represent a physiological source of PAI-2, and these cells not only accumulate PAI-2 intracellularly but also secrete PAI-2 (16). Secretion of PAI-2 by peripheral blood monocytes occurs via an ER-Golgi independent pathway, which results in an abundance of
$47 \mathrm{kDa}$ non-glycosylated PAI-2 in the medium surrounding monocytes (17). This is in contrast to other cell types such as U937 cells, where PAI-2 is secreted as a $60 \mathrm{kDa}$ glycosylated PAI-2 (45). We found that secretion of PAI-2 by monocytes into the overlying fibrin clot occurred rapidly, and PAI-2 penetrated the fibrin clot and inhibited fibrin clot lysis within the time course of the clot lysis assay. Antibodies to PAI-2 neutralized the inhibitory effect, but this neutralization was not complete even at a 2000-fold excess of antibody concentration over PAI-2 antigen. It is possible that PAI-2 cross-linked to fibrin is not readily accessible to antibody. It is interesting that non-glycosylated PAI-2 is secreted by monocytes, since it has been postulated that glycosylation of PAI-2 at asparagine 75 prevents cross-linking of PAI-2 via glutamine residues 83 to 86 (12). Non-glycosylated PAI-2 secreted by monocytes would therefore be available for cross-linking by transglutaminases.

PAI-2 synthesis by monocytes is up-regulated by both thrombin and D-dimer $(16,46)$. Thrombin, which is present in the fibrin clot, may act to maintain synthesis and secretion of PAI-2 by monocytes, acting as a positive feedback loop. D-dimer is produced as fibrin is degraded and this mechanism may also act to mediate persistence of fibrin by an up-regulation in PAI-2 by monocytes.

PAI-2 production by monocytes is an efficient inhibitor of u-PAmediated fibrin clot lysis. The physiological relevance of this is currently under investigation, since u-PA is highly expressed in the atherosclerotic plaque (5). It is becoming increasingly evident that PAI-2 is present in many situations, including the atherosclerotic plaque and thrombi, where monocytes are a major cell type. Cross-linking of PAI-2 serves to localize activity at the fibrin surface, where it may contribute to persistence of fibrin, either within the fibrin clot or inflammatory lesions.

\section{Acknowledgments}

We thank Biopharm UK Ltd for the gift of Tridegin and Dr PJ Gaffney (NIBSC) for the monoclonal antibody to fibrin.

\section{References}

1. Booth NA. Natural inhibitors of fibrinolysis. In: Haemostasis and Thrombosis. Bloom AL, Forbes CD, Thomas DP, Tuddenham EGD, eds., 3rd edn. Churchill Livingstone 1994: pp 699-717.

2. Smith EB, Thompson WD. Fibrin as a factor in atherogenesis. Thromb Res 1994; 73: 1-19.

3. Schneiderman J, Sawdey MS, Keeton MR, Bordin GM, Bernstein EF, Dilley RB, Loskutoff DJ. Increased type 1 plasminogen activator inhibitor gene expression in atherosclerotic human arteries. Proc Natl Acad Sci USA 1992; 89: 6998-7002.

4. Lupu F, Heim D, Bachmann F, Kruithof EKO. Localization and production of plasminogen activator inhibitor-1 in human healthy and atherosclerotic arteries. Arterioscler Thromb 1993; 13: 1090-100.

5. Robbie LA, Booth NA, Brown PAJ, Bennett B. Inhibitors of fibrinolysis are elevated in the atherosclerotic plaque. Arterioscler Thromb Vasc Biol 1996; 16: 539-45.

6. Robbie LA, Bennett B, Croll AM, Brown PAJ, Booth NA. Proteins of the fibrinolytic system in human thrombi. Thromb Haemost 1996; 75: $127-33$.

7. Robbie LA, Wright GA, Booth NA, Bennett B. Inhibitors of fibrinolysis in normal and diseased human arteries. Thromb Haemost 1997; Suppl: PS-2277 (abstr).

8. Kruithof EKO, Tran-Thang C, Gudinchet A, Hauert J, Nicoloso G, Genton C, Welti H, Bachman F. Fibrinolysis in pregnancy: A study of plasminogen activator inhibitors. Blood 1987; 69: 460-8. 
9. Lyons-Giordano B, Loskutoff D, Chen C-S, Lazurus G, Keeton M, Jensen PJ. Expression of plasminogen activator inhibitor type 2 in normal and psoriatic epidermis. Histochem 1994; 101: 105-12.

10. Whawell SA, Vipond MN, Scott-Combes DM, Thompson JN. Plasminogen activator inhibitor 2 reduces peritoneal activity in inflammation. Br J Surg 1993; 80: 107-9.

11. Astedt B, Hagerstrand I, Lecander I. Cellular localization in placenta of placental type plasminogen activator inhibitor. Thromb Haemost 1986; 56: 63-9.

12. Kruithof EKO, Baker MS, Bunn CL. Biological and clinical aspects of plasminogen activator inhibitor type 2. Blood 1995; 86: 4007-24.

13. Remold O'Donnell E. The ovalbumin family of serpin proteins. FEBS Lett 1995; 315: 105-8.

14. Zoellner H, Wojta J, Gallicchio M, McGrath K, Hamilton JA. Cytokine regulation of the synthesis of plasminogen activator inhibitor- 2 by human vascular endothelial cells. Thromb Haemost 1993; 69: 135-40.

15. Pytel BA, Peppel K, Baglioni C. Plasminogen activator inhibitor type-2 is a major protein induced in human fibroblasts and SK-MEL-109 melanoma cells by tumor necrosis factor. J Cell Physiol 1990; 144: 416-22.

16. Ritchie H, Jamieson A, Booth NA. Thrombin modulates synthesis of plasminogen activator inhibitor 2 (PAI-2) by human peripheral blood monocytes. Blood 1995; 86: 3428-35.

17. Ritchie H, Booth NA. Secretion of plasminogen activator inhibitor 2 by human peripheral blood monocytes occurs via an endoplasmic reticulumGolgi-independent pathway. Exp Cell Res 1998; 242: 439-50.

18. Kirchheimer JC, Remold HG. Functional characteristics of receptor-bound urokinase on human monocytes: catalytic efficiency and susceptibility to inactivation by plasminogen activator inhibitors. Blood 1989; 74: 1396-1402.

19. Kumar S, Baglioni C. Protection from tumor necrosis factor-mediated cytolysis by overexpression of plasminogen activator inhibitor type-2. J Biol Chem 1991; 266: 20960-4.

20. Gan H, Newman GW, Remold HG. Plasminogen activator inhibitor type 2 prevents programmed cell death of human macrophages infected with Mycobacterium avium, serovar 4. J Immunol 1995; 155: 1304-15.

21. Dickinson JL, Bates EJ, Ferrante A, Antalis T. Plasminogen activator inhibitor type 2 inhibits tumor necrosis factor $\alpha$-induced apoptosis. J Biol Chem 1995; 270: 27894-904.

22. Jensen PH, Schuler E, Woodrow G, Richardson M, Goss N, Hujrup P, Petersen TE, Rasmussen LK. A unique interhelical insertion in plasminogen activator inhibitor-2 contains three glutamines, Gln83, Gln84, Gln86, essential for transglutaminase-mediated cross-linking. J Biol Chem 1994; 269:15394-8.

23. Jensen PH, Lorand L, Ebbesen P, Gliemann J. Type-2 plasminogen activator inhibitor is a substrate for trophoblast transglutaminase and factor XIIIatransglutaminase-catalyzed cross linking to cellular and extracellular structures. Eur J Biochem 1993; 214: 141-6.

24. Jensen PJ, Wu Q, Janowitz P Ando Y, Schechter NM. Plasminogen activator inhibitor type 2: an intracellular keratinocyte differentiation product that is incorporated into the cornified envelope. Exp Cell Res 1995; 217: 65-72.

25. Aeschlimann D, Paulsson M. Transglutaminases: protein cross-linking enzymes in tissues and body fluids. Thromb Haemost 1994; 71: 402-15.

26. Gorman JJ, Folk JE. Structural features of glutamine substrates for transglutaminases. J Biol Chem 1981; 256: 2712-6.

27. Sakata Y, Aoki N. Significance of cross-linking of $\alpha_{2}$-plasmin inhibitor to fibrin in inhibition of fibrinolysis and in hemostasis. J Clin Invest 1982; 69: 536-42.

28. Greenberg CS, Achyuthan KE, Borowitz MJ, Shuman MA. The transglutaminase in vascular cells and tissues could provide an alternative pathway for fibrin stabilization. Blood 1987; 70: 702-8.
29. Robbie LA, Booth NA, Croll AM, Bennett B. The roles of $\alpha_{2}$-antiplasmin and plasminogen activator inhibitor 1 (PAI-1) in the inhibition of clot lysis. Thromb Haemost 1993; 70: 301-6.

30. Booth NA, MacGregor IR, Hunter NR, Bennett B. Plasminogen activator inhibitor from endothelial cells. Purification and partial characterization. Eur J Biochem 1987; 165: 595-600.

31. Sancho ES, Tonge DW, Hockney RC, Booth NA. Purification and characterization of active and stable recombinant plasminogen-activator inhibitor accumulated at high levels in Escherichia coli. Eur J Biochem 1994; 224 : 125-31.

32. Steven J, Cottingham IR, Berry SJ, Chinery SA, Goodey AR, Courtney M, Ballance DJ. Purification and characterisation of plasminogen activator inhibitor 2 produced in Saccharomyces cerevisiae. Eur J Biochem 1991; 196: 431-8.

33. Reith A, Bennett B, Booth NA. Plasminogen activator inhibitor (PAI-2) in pregnancy plasma and ovarian cysts, studied by zymography after non denaturing gel electrophoresis. Fibrinolysis 1989; 3: 159-63.

34. Finney S, Seale L, Sawyer RT, Wallis RB. Tridegin, a new peptidic inhibitor of factor XIIIa, from the blood sucking leech, Haementeria ghilianii. Biochem J 1997; 324: 797-805.

35. Raut S, Gaffney P. Evaluation of the fibrin binding profile of two anti-fibrin monoclonal antibodies. Thromb Haemost 1996; 76: 56-64.

36. Ritchie H, Jamieson A, Booth NA. Regulation, location and activity of plasminogen activator inhibitor 2 (PAI-2) in peripheral blood monocytes, macrophages and foam cells. Thromb Haemost 1997; 77:1168-73.

37. Leung K-C, Byatt JA, Stephens RW. The resistance of fibrin-stimulated tissue plasminogen activator to inactivation by a class PAI-2 inhibitor (Minactivin). Thromb Res 1987; 46: 755-66.

38. Lijnen HR, Bachmann F, Collen D, Ellis V, Pannekoek H, Rijken DC, Thorsen S. Mechanisms of plasminogen activation. J Int Med 1994; 236: 415-20.

39. Ellis V, Pyke C, Eriksen J, Solberg H, Dano K. The urokinase receptor: involvement in cell surface proteolysis and cancer invasion. Ann NY Acad Sci 1992: 13-8.

40. Carmeliet P, Schoonjans L, Kieckens L, Ream B, Degen J, Bronson R, De Vos R, van den Oord JJ, Collen D, Mulligan RC. Physiological consequences of loss of plasminogen activator gene function in mice. Nature 1994; 368: 419-24.

41. Hettasch JM, Haroon ZA, Lai TS, Slaughter TF, Greenberg CS. Tissue transglutaminase as a wound healing enzyme that triggers platelet activation. Thromb Haemost 1997; Suppl: PS-1439 (abstr).

42. Tamaki T, Aoki N. Cross-linking of $\alpha_{2}$-plasmin inhibitor to fibrin catalyzed by activated fibrin-stabilizing factor. J Biol Chem 1982; 257: 14767-72.

43. Gruther MG, Priestle JP, Rahuel J, Grossenbacher H, Bode W, Hofsteenge J, Stone SR. Crystal structure of the thrombin-hirudin complex: a novel mode of serine protease inhibition. EMBO J 1990; 9: 2361-5.

44. Seale L, Finney S, Sawyer RT, Wallis RB. Tridegin, a novel inhibitor of factor XIIIa from the leech, Haementeria ghilianii, enhances fibrinolysis. Thromb Haemost 1997; 77: 959-63.

45. Genton C, Kruithof EKO, Schleuning W-D. Phorbol ester induces the biosynthesis of glycosylated and nonglycosylated plasminogen activator inhibitor 2 in human U937 lymphoma cells. J Cell Biol 1987; 104: 705-12.

46. Robson SC, Shephard EG, Kirsch RE. Fibrin degradation product D-dimer induces the synthesis and release of biologically active IL-1 $1 \beta$, IL- 6 and plasminogen activator inhibitors from monocytes in vitro. Br J Haematol 1994; 86: 322-6.

Received June 29, 1998 Accepted after revision September 22, 1998 